\title{
PESQUISA DE Bacillus cereus EM PRODUTOS FARINÁCEOS E A BASE DE SOJA
}

\author{
W. F. MARTINS ${ }^{1}$, G. NICOLETTI ${ }^{1}$, C. SILVEIRA ${ }^{1}$, F.S.N. MELO ${ }^{2}$, M.S.A. RODRIGUES ${ }^{3}$, \\ D.S. SEVERO ${ }^{3}$, COSTA, W. $\mathrm{M}^{3}$ e A. dos S. ARAUJO ${ }^{3}$ \\ ${ }^{1}$ Universidade Federal de Santa Catarina, Departamento de Engenharia Química e Engenharia de \\ Alimentos \\ ${ }^{2}$ Universidade Federal da Paraíba , Centro de Tecnologia \\ ${ }^{3}$ Universidade Federal de Campina Grande, Centro de Ciência e Tecnologia Agroalimentar E- \\ mail para contato: wiaslanmartins@gmail.com
}

\begin{abstract}
RESUMO - A presença de Bacillus cereus em alimentos é relativamente frequente. Certas cepas são importantes por provocarem toxifecções alimentares. São encontradas, principalmente, em cereais e produtos amiláceos. O objetivo deste trabalho foi avaliar a contaminação por $B$. cereus em produtos farináceos e a base de soja. Na análise de $B$. cereus utilizou-se o meio de cultura ágar MYP (Mannitol yolk polymixin Agar), as placas foram incubadas a $30{ }^{\circ} \mathrm{C}$ por $24 \mathrm{~h}$. As colônias presuntivas de $B$. cereus foram isoladas e, realizados os testes de coloração de gram, catalase, motilidade, liquefação da gelatina, crescimento rizoide e hidrólise do amido. A contaminação por $B$. cereus atingiu valor máximo de $3,95 \times 10^{4} \mathrm{UFC}^{-1} \mathrm{~g}^{-1}$ nos produtos farináceos e de $7,99 \times 10^{4} \mathrm{UFC} . \mathrm{g}^{-1}$ nos produtos a base de soja. As elevadas contagens indicam falhas nos processos de fabricação e riscos a saúde de quem os consome. Todos os produtos encontram-se fora dos padrões microbiológicos permitidos pela legislação vigente.
\end{abstract}

\section{INTRODUÇÃO}

Bacillus cereus é um microrganismo gram positivo amplamente distribuído na natureza, sendo o solo seu reservatório natural. A presença da bactéria ou de seus esporos em alimentos é relativamente frequente (Soares et al., 2008). Este gênero possui células em bastonetes, móveis ou não, incluindo espécies aeróbias e facultativas. Produzem esporos, sendo, por isso, importantes nos casos de alimentos que sofreram tratamentos térmicos (esterilização ou pasteurização) ou aquecimentos (cocção, fritura), isto porque os esporos são resistentes a temperaturas elevadas, podendo sobreviver a certos tipos de aquecimento. Posteriormente podem germinar (dependendo das condições) e se multiplicar, provocando deteriorações ou doenças de origem alimentar.

Certas cepas de B.cereus são importantes por provocarem toxifecções alimentares. São encontradas, principalmente, em cereais e produtos amiláceos. Outras podem causar toxinose, sendo encontradas principalmente no arroz (Gava et al., 2008).

Dentre as formas esporuladas, Bacillus cereus destaca-se na indústria alimentícia como agente causador de toxinfecção alimentar, além de provocar grandes prejuízos econômicos por ser um potencial deteriorante de alimentos (Cosentino et al., 1997). 
Os fatores que contribuem para a presença deste microrganismo estão relacionados à higiene inadequada dos manipuladores e manutenção do alimento à temperatura ambiente por longo intervalo de tempo. Sendo assim, são importantes as características e propriedades do alimento seguro, a importância dos manipuladores de alimento e as necessidades de utilização de Boas Práticas de Fabricação (BPF). Além disso, é destacada a importância da alimentação como necessidade humana, as exigências por qualidade alimentar e as regras de higiene propostas pela ANVISA.

Diante do exposto, o objetivo deste trabalho foi avaliar a contaminação por B. cereus em diferentes produtos farináceos e a base de soja.

\section{MATERIAL E MÉTODOS}

O trabalho foi desenvolvido no Laboratório de Microbiologia do centro Vocacional Tecnológico (CVT-Pombal/PB). Os produtos farináceos e a base de soja foram obtidos no comércio de Pombal-PB. Os produtos farináceos foram identificados como as amostras de 1 a 4 e os produtos a base de soja como as amostras de 5 a 10. As amostras de farinha continham os seguintes cereais: trigo, milho e arroz (amostra 1), trigo, aveia, arroz, cevada e milho (amostra 2), trigo, cevada e aveia (amostra 3) e trigo, arroz, aveia, cevada e milho (amostra 4). Os produtos a base de soja foram: grãos de soja (amostra 5), farinha de soja (amostra 6), farofa de soja (amostra 7), extrato de soja (amostra 8), proteína texturizada de soja (amostra 9) e bebida de soja (amostra 10)

Para a realização da análise de B.cereus, as amostras (25 g/amostra) foram diluídas em 225 $\mathrm{mL}$ de água peptonada $0,1 \%$ e homogeneizadas em mesa agitadora orbital marca NOVA ÉTICA ${ }_{\circledast}$ em 200rpm durante $25 \mathrm{~min}$. Alíquotas de diluições sucessivas das amostras $\left(10^{-1}, 10^{-2}\right.$ e $\left.10^{-3}\right)$ foram inoculadas em placas de Petri contendo ágar MYP (Mannitol yolk polymixin Agar) e incubadas a $30^{\circ} \mathrm{C}$ por $24 \mathrm{~h}$, em duplicata.

Cinquenta a duzentos e cinquenta colônias presuntivas de $B$. cereus não fermentadoras de manitol e produtoras de lecitinase (Figura 1) foram isoladas e estocadas em tubo inclinado contendo ágar nutriente (Nutrient Agar) a $35^{\circ} \mathrm{C}$. A partir do tubo inclinado foram realizados os testes de catalase, motilidade, liquefação da gelatina, hidrólise do amido e crescimento rizoide.

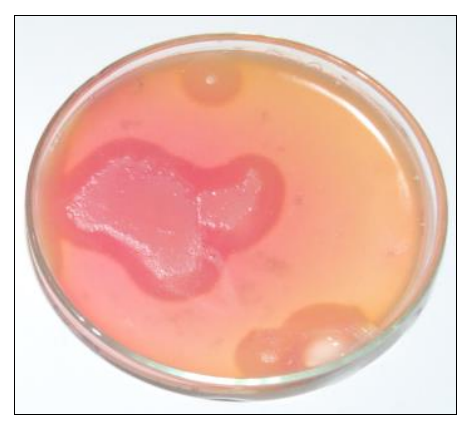

Figura 1 - Colônias de Bacillus cereus em placas de Petri contendo ágar MYP (Mannitol yolk polymixin Agar) 
No teste de catalase foi adicionado gotas de peróxido de hidrogênio a 3\% nas cepas e verificou-se a produção ou não de bolhas. No teste de motilidade, as cepas foram inoculadas com alça de platina em tubos contendo ágar motilidade (Agar Motility Medium) e incubadas a $35^{\circ} \mathrm{C}$ por 18 a $24 \mathrm{~h}$. Após a incubação, verificou-se o tipo de crescimento. No teste de liquefação da gelatina utilizou-se Ágar Gelatina em tubos de ensaio esterilizados e em seguida as cepas foram inoculadas com auxilio de uma alça platina e incubadas a $35^{\circ} \mathrm{C}$ por $24 \mathrm{~h}$. Após a incubação os tubos foram colocados em geladeira durante $30 \mathrm{~min}$, em seguida verificou-se se o meio permanece sólido ou não. Para o teste de hidrólise do amido utilizou-se o meio de cultura Agar Amido que foi adicionado em placa estéril com e após solidificar, inoculou-se em forma de estria as colônias do tubo inclinado, incubou-se de 30 a $35^{\circ} \mathrm{C}$ durante $24 \mathrm{~h}$. Em seguida foi adicionado na placa cerca de 3 a $4 \mathrm{~mL}$ de solução de lugol. Após alguns segundos observou-se o escurecimento do meio, e a presença ou ausência de uma zona clara ao redor da colônia. No teste de crescimento rizoide utilizou-se o meio de cultura ágar nutriente (Nutrient Agar) foi adicionado em placa estéril com e após solidificar, inoculou-se a cepa no centro da placa e incubou-se a $35^{\circ} \mathrm{C}$ por 48 a $72 \mathrm{~h}$. Após incubação verificou-se o tipo de crescimento. Os procedimentos analíticos microbiológicos foram realizados de acordo as diretrizes e metodologias recomendadas pelo Ministério da Agricultura e do Abastecimento (Brasil, 2003).

\section{RESULTADOS E DISCUSSÃO}

A contaminação indicativa de $B$. cereus nas farinhas atingiu valor máximo de 3,95 x $10^{4}$ UFC.g $\mathrm{g}^{-1}$ (Amostra 2) e nos produtos a base de soja valor máximo de 7,99 x 10 UFC.g $^{-1}$ (Amostra 10) (Figura 2). Foram considerados positivos os isolados que apresentaram colônias rugosas, secas, com coloração rosada, rodeada por halo de precipitação branco e dentro dos testes, foi móvel, crescimento rizóide negativo, Gram-positiva, catalase positiva (Figura 3), hidrólise do amido positiva (Figura 4), liquefação de gelatina positiva e produziram lecitinase. As outras amostras que tiveram crescimento de espécies do gênero Bacillus que não se enquadraram nestas características foram consideradas negativas (amostra 1), a mesma apresentou hidrólise do amido negativa.

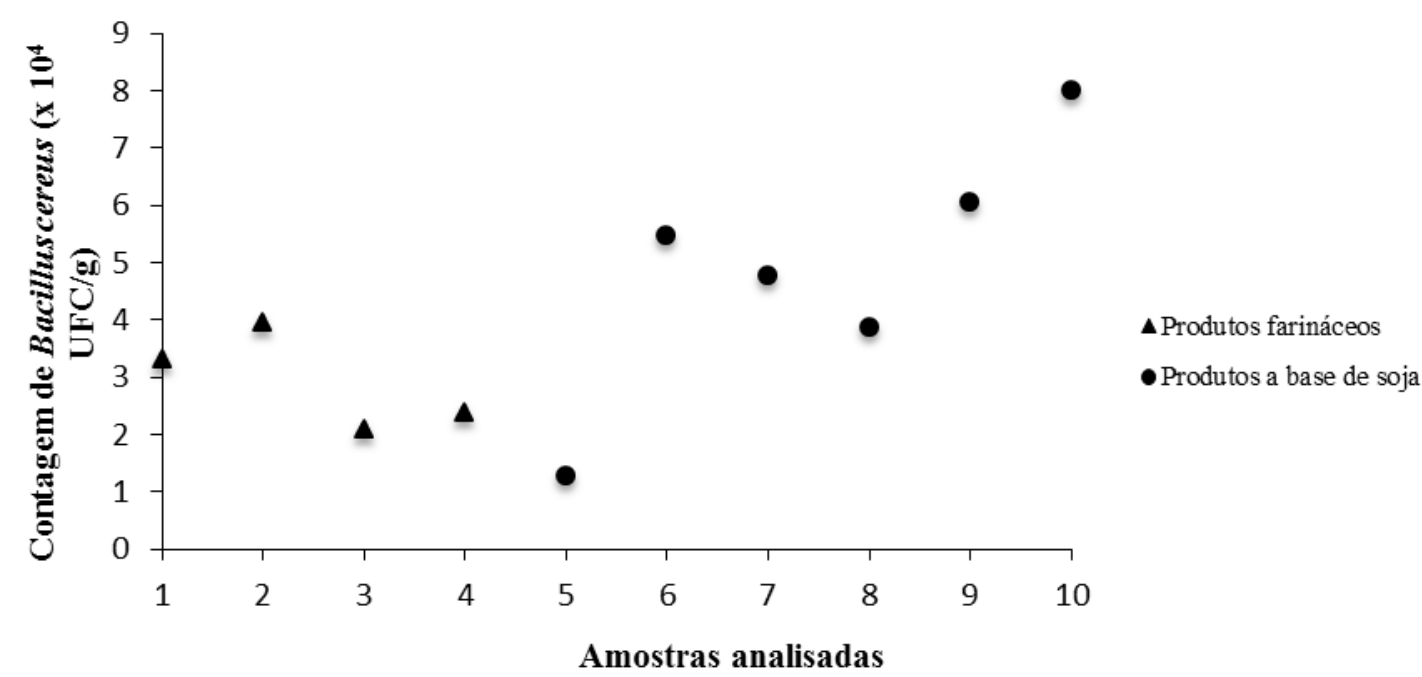

Figura 2- Contagens de Bacillus cereus em unidades formadoras de colônias por grama 
(UFC/g) das amostras de farinha de multicereais ( amostras de 1 a 4) e produtos a base de soja (amostras de 5 a 10)

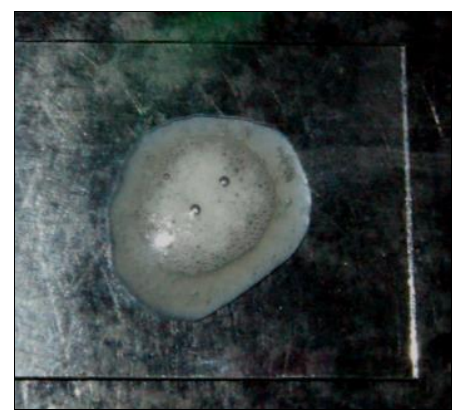

Figura 3 - Teste de catalase nas colônias de B. cereus realizado com adição de gotas de peróxido de hidrogênio a $3 \%$ nas cepas

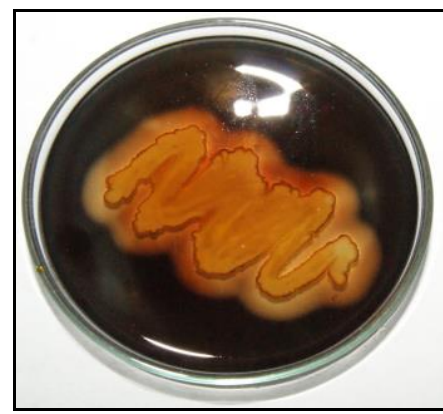

Figura 4 - Colônias de B. cereus em Agar Amido e adicionadas de lugol (teste de hidrólise do amido positivo)

No entanto todas as amostras apresentaram contaminação na ordem de $10^{4}$ UFC.g ${ }^{-1}$ como mostra a Figura 2, o que indica falhas no processo de fabricação dos produtos, principalmente do ambiente de processamento, visto que o B. cereus encontra-se no ambiente em geral.

Silva et al. (2007) avaliaram a composição microbiológica de farinha de algaroba e valores de B. cereus foram inferiores $\left(<10 \mathrm{UFC} \cdot \mathrm{g}^{-1}\right)$ aos limites estabelecidos pela Resolução $-\mathrm{RDC} \mathrm{n}^{\circ}$ 12, de 02 de janeiro de 2001 confirmando que o processo utilizado para produção da farinha é satisfatório do ponto de vista da segurança microbiológica. Zanatta et al. (2010) avaliaram a presença de B.cereus em farinhas de beterraba, cenoura e espinafre, encontrando valores abaixo do permitido pela legislação acima citada $\left(<1,0 \times 10^{3} \mathrm{UFC} / \mathrm{g}\right)$ para todas as farinhas, indicando boas condições higiênicos-sanitárias da matéria-prima e da manipulação das amostras desidratadas. Chisté et al. (2007) identificaram os contaminantes microbiológicos em farinha de mandioca durantes as etapas do processamento e o B. cereus não foi encontrado nas etapas de lavagem, trituração e prensa, mas, encontrado valor de $<1,0 \times 10^{1} \mathrm{UFC} / \mathrm{g}$ na farinha de mandioca, dentro do limite permitido pela legislação já citada. Não há trabalhos na literatura sobre pesquisa de $B$. cereus em produtos a base de soja.

O B.cereus é largamente distribuído na natureza, sendo o solo o seu reservatório natural. Por esta razão, contamina facilmente alimentos como: vegetais, cereais, etc. (Franco, 1996). A contaminação de alimentos por B.cereus constitui não somente uma importante causa de 
deterioração, mas também está associada à ocorrência de dois tipos de síndrome, devidos à ingestão de alimentos contaminados com cepas patogênicas produtoras de toxinas, uma emética e outra diarréica (Agata et al., 2002; Mcelroy et al., 2000; Tsen et al., 2000). A toxina do tipo diarreico é, muito possivelmente, produzida no trato intestinal, sendo os fatores de virulência ainda não completamente caracterizados (Ghelardi et al., 2002; Granum, 1994; Minnaard et al., 2001).

No presente estudo, a presença de B. cereus nas amostras de farinhas de multicereais e nos produtos a base de soja encontra-se fora dos padrões permitidos pela legislação (Resolução RDC $\mathrm{n}^{\circ} 12$ de 02.01.01 da Agencia Nacional de Vigilância Sanitária), que é de 5 x 10 ${ }^{2}$ UFC.g $^{-1}$ (Brasil, 2001).

\section{CONCLUSÕES}

O B. cereus foi encontrado nos produtos farináceos (amostras 2, 3 e 4) e nos produtos base de soja (amostras 5, 6, 7, 8, 9 e 10) confirmada através das análises bioquímicas realizadas. Considerando que a bactéria exige grande capacidade de sobrevivência e se multiplica em ampla faixa de temperatura, a transferência de um pequeno número de células pode dar origem a populações causadoras de doenças de origem alimentar, desde que o alimento fique estocado por períodos que assim o permitam.

As elevadas contagens indicam falhas nos processos de fabricação e riscos a saúde de quem os consomem. Todos os produtos encontram-se fora dos padrões microbiológicos permitidos pela legislação vigente.

\section{REFERÊNCIAS}

AGATA, N.; OHTA, M; YOKOYAMA K. Production of Bacillus cereus emetic toxin (cereulide) in various foods. Int. J. Food Microbiol, n. 73, p. 23-27, 2002.

BRASIL. Ministério da Saúde. Agência Nacional da Vigilância Sanitária. Resolução RDC nº12, de 2 de janeiro de 2001. Regulamento técnico sobre padrões microbiológicos em alimentos.

BRASIL. Ministério da Agricultura, Pecuária e Abastecimento. Instrução Normativa $\mathrm{n}^{\circ}$ 62, de 26 de agosto de 2003. Oficializa os Métodos Analíticos Oficiais para Análises Microbiológicas para Controle de Produtos de Origem Animal e Água. Diário Oficial da República Federativa do Brasil, Brasília, 18/09/2003.

CHISTÉ, R.C.; Kelly de Oliveira COHEN, K.O.; Erla de Assunção MATHIAS, E.A.; RAMOA JÚNIOR, A.G.A. Estudo das propriedades físico-químicas e microbiológicas no processamento da farinha de mandioca do grupo d'água. Ciência e Tecnologia Alimentar, Campinas, 27(2): 265-269, abr.-jun. 2007.

COSENTINO, S.; MULARGIA, A.F.; PISANO, B. et al. Incidence and biochemical characteristics of Bacillus flora in Sardinian dairy products. Int. J. Food Microbiol., v.38, p.235238, 1997.

FRANCO, B. D. G. M.; LANDGRAF, M. Microbiologia dos Alimentos. 1996. 215p. São Paulo: Editora Atheneu 
GAVA, A.J.; SILVA, C.A.B.; FRIAS, J.R.G. Tecnologia de alimentos: Princípios e aplicações. São Paulo: Nobel, 2008.

GHELARDI, E.; CELANDRONI, F.; SALVATTI.: BARSOTTI, C.; BAGGIANI, A.; SENESI, S. Identification and characterization of toxigenic Bacillus cereus isolates responsible for two foodpoisoning aulbreaks. FEMS Microbiology Letters. v. 208. n. 1. p. 129-134, 2002.

GRANUM, P.E. Bacillus cereus and its toxins. J. Appl. bacterial., v. 76. p. 61-66. 1994.

SOARES, C. M.; VALADARES, G. F.; AZEREDO, R. M. C.; KUAYE, A. Y. Contaminação ambiental e perfil toxigênico de Bacillus cereus isolados em serviços de alimentação. Ciência Rural, Santa Maria, v.38, n.2, p.504-510, mar-abr, 2008.

MCELROY, D. M.; JAYKUS, L. A.; FOEGEDING, P. M. Validation and Analysis of Modeled Predictions of Growth of Bacillus cereus Spores in Boiled Rice. J. Food. Protec., v. 2, n. 63, p. 268-272, 2000.

MINNAARD, J.; HUMEN, M.; PÉREZ, P.F. Effect of Bacillus cereus Exocelullar Factors on Human Intestinal Epithelial Cells. J. Food. Protec., v. 10. N. 64 p. 1535-1541, 2001.

SILVA, C.G.M.; MELO FILHO, A.B.; PIRES, E.F; STAMFORD, T.L.M. Caracterização físicoquímica e microbiológica da farinha de algaroba (Prosopis juliflora (Sw.) DC). Ciência e Tecnologia Alimentar., Campinas, 27(4): 733-736, out.-dez. 2007.

TSEN, H. Y.; CHEN, M. L.; HSIEH, Y. M.; SHEU, S. J.; CHEN, Y. L. Bacillus cereus Group Strains, their Hemolysin BL Activity, and their Detection in Foods Using a 16s RNA and Hemolysin BL Gene-Targeted Multiplex Polymerase Chain Reaction System. J. Food Protec., v. 11, n. 63, p. 1496-1502, 2000.

ZANATTA, C. L.; SCHLABITZ, C.; ETHUR, E. M. Physico-chemical and microbological evaluation of fl our obtained from vegetable not conforming to marketing. Alim. Nutr., Araraquara, v. 21, n. 3, p. 459-468, jul./set. 2010. 